\title{
Assessment of colorectal cancer awareness in patients admitted to the general surgery outpatient clinic
}

\author{
Cemile İdiz ${ }^{1} \odot$, Çoşkun Çakır²$^{2}$, Murat Keğin $^{3} \odot$, Abdülhakim İbrahim Ulusoy ${ }^{4}$ \\ ${ }^{1}$ Department of Internal Medicine, Istanbul University Istanbul School of Medicine, Istanbul, Turkey \\ ${ }^{2}$ Department of General Surgery, Istanbul Training and Research Hospital, Istanbul, Turkey \\ ${ }^{3}$ Department of General Surgery, Gaziosmanpaşa Taksim Training and Research Hospital, Istanbul, Turkey \\ ${ }^{4}$ Department of General Surgery, Okmeydanı Training and Research Hospital, İstanbul, Turkey
}

\begin{abstract}
Objectives: Colorectal cancer could be prevented with some basic lifestyle modifications.In this study we query the awareness of the participants about colorectal cancer who visit the general surgery outpatients clinic. Methods: A questionnaire consisting of 13 questions was applied to the participants as well as demographic data. Differences in awareness of screening and risk factors were sub-grouped according to age, BMI, education, employment status, monthly income, marital status, status of first-degree relative colorectal cancer, smokingalcohol use status and exercise status.

Results: The most known screening method was colonoscopy with $73.6 \%$, while the least known screening method was sigmoidoscopy with $13.4 \%$. Also, the best known risk factor was smoking with $67.4 \%$, while the least known risk factor was type 2 diabetes with $29.8 \%$. In our study, those over 45 years of age, having higher education, working, having more monthly income, having a family history of colorectal cancer and exercising regularly had more awareness about colorectal cancer screening and risk factors.

Conclusions: Our study had high levels of awareness compared to developing countries, however, awareness levels are not high enough and it is possible to increase these rates by educating the patients on cancer awareness.
\end{abstract}

Keywords: Colorectal cancer, awareness, general surgery

A ccording to World Health Organization (WHO) data, cancer is the second most common cause of death in the world and it is estimated that it causes 9.6 million deaths in 2018 [1]. The economic burden of cancer increases with each passing day, and the economic cost of cancer in 2010 is estimated to be US \$ 1.16 trillion [2].

Colorectal cancer is among the most common types of cancer worldwide. Colorectal cancer is the third most common type of cancer in both men and women. According to the data of the WHO, 694 thousand people died in 2012 due to colorectal cancer and this number increased to 862 thousand people in 2018 $[1,3]$.

According to the Turkish Ministry of Health Cancer Statistics, 2004-2006, the incidence rate of colorectal cancer standardized by age was 17.0 per hundred thousand people in men, 11.7 per hundred thousand people in women in Turkey [4, 5]. Although colorectal cancer screening tests are performed rou- 
tinely in our country as in many countries, however the lack of sufficient information about colorectal cancer decreases the rate of applications of these tests [6, 7].

In many studies related to colorectal cancer awareness, inadequate awareness among individuals is observed especially in middle and underdeveloped countries. These studies are usually based on random populations and a small number of them were performed on health workers [7-13]. Although the diagnosis of colorectal cancer is usually diagnosed by some clinical branches which care to gastrointestinal system such as general surgery, however we did not find any study evaluating the colorectal cancer awareness levels of patients coming to these outpatient clinics.

In this study, we aimed to determine the level of awareness of colorectal cancer and knowledge about colorectal cancer screenings in patients who applied to general surgery outpatients clinic where patients with rectal bleeding applied and colorectal cancer was most frequently diagnosed in Turkey.

\section{METHODS}

This observational study was descriptive and has cross-sectional design and it was initiated following the approval of the local human ethical committee and was conducted between May 2019 and August 2019 in patients admitted to the general surgery outpatient clinic of the three different hospital. Clinical trials registrations were performed (NCT04020614). All patients included in the study signed an informed consent form. The questionnaires were conducted with the participants by face to face question-answer method. The flow diagram of the participants is shown in Fig. 1.

Inclusion criterias were adult individuals older than 18 years and younger than 80 years who do not have a mental disorder such as Alzheimer's or mental retardation and agreeing to participate in the study, and the exclusion criteria are refusing to participate in the study, being under 18 or over 80 , having known mental disability and colorectal cancer. In addition to demographic data, a questionnaire which was defined by Briant et al. [14] consisting of 13 questions was used to determine the level of colorectal cancer awareness level. The first 5 questions of the questionnaire relate to the level of awareness about colorectal cancer screening and the next 8 questions relate to the level of knowledge about colorectal cancer risk factors.

Differences in screening and risk factors were subgrouped and analyzed according to age, Body mass index (BMI), education, employment status, monthly income, marital status, the status of first-degree relative colorectal cancer, smoking-alcohol use status

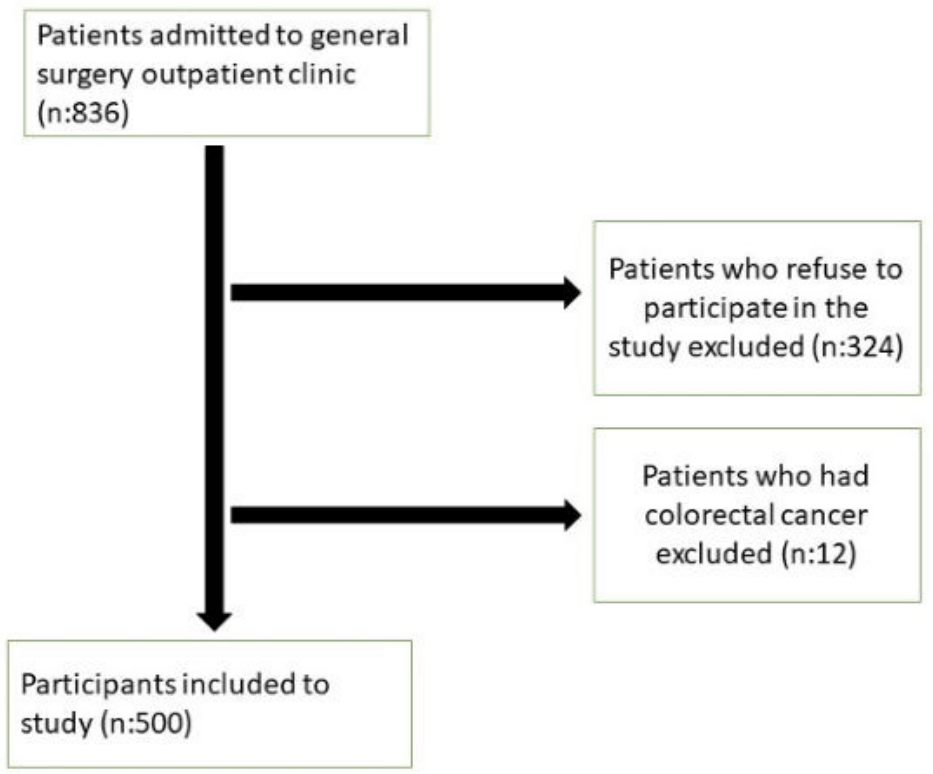

Fig. 1. Flow diagram of the participants. 
and exercise status. The questions in the study were performed by asking the patients face to face and no intervention was made to the volunteers. The survey duration for each patient lasted approximately 10 minutes.

\section{Statistical Analysis}

The SPSS 22.0 (SPSS Inc., Chicago, IL, USA) computer program was used for analyzing the data. Descriptive statistics are shown in numbers (n) and percentages $(\%)$. The chi square test was used to analyze the relationship between screening and risk factors of the subgroups formed according to the demographic characteristics of the patients. A level of $p<0.05$ was set as statistically significant.

\section{RESULTS}

The mean age of the 500 volunteers in the study was $47.07 \pm 11.77$ years and the female/male ratio was found to be 1.25. All the volunteers who participated in the study answered all the questions in the questionnaire and their demographic characteristics were given in Table 1 .

The responses of the volunteers about colorectal cancer screening methods are given in Table 2 and the answers given to colorectal cancer risk factors are shown in Table 3. The $385(77 \%)$ of the participants had information about any colorectal cancer screening method, colonoscopy was the most known screening method with $73.6 \%$, while sigmoidoscopy was the least known screening method with $13.4 \%$. Also, the best known risk factor was smoking with $67.4 \%$, while the least known risk factor was type 2 diabetes with $29.8 \%$.

When the awareness of screening and risk factors were evaluated separately according to the volunteer descriptive data; Young people have less knowledge about Fecal occult blood test (FOBT) than the 45 upper individuals $(33.7 \%$ vs $42.8 \%, p=0.042)$. Individuals over 45 years of had more information about aging which increase the risk of colorectal cancer than young people $(42.8 \%$ vs $33.7 \%, p=$ 0.042 ). Individuals over 45 years of age had more information about smoking which increases the risk of colorectal cancer $(71.4 \%$ vs $61.2 \%, p=0.018)$. Individuals over 45 years of age were more aware
Table 1. Demographic characteristics of the participants

\begin{tabular}{|c|c|}
\hline Characteristics & n (\%) \\
\hline \multicolumn{2}{|l|}{ Gender } \\
\hline Female & $278(55.6)$ \\
\hline Male & $222(44.4)$ \\
\hline \multicolumn{2}{|l|}{ Age } \\
\hline$<45$ years & $196(39.2)$ \\
\hline$>45$ years & $304(60.8)$ \\
\hline \multicolumn{2}{|l|}{ BMI } \\
\hline$<25$ (Normal) & $162(32.4)$ \\
\hline 25-30 (Overweight) & $228(45.6)$ \\
\hline$>30$ (Obese) & $110(22.0)$ \\
\hline
\end{tabular}

Education

Elementary school

$212(42.4)$

High school

$203(40.6)$

Graduate level or higher

$85(17.0)$

Working condition

Working

$204(40.8)$

Not Working

$173(34.6)$

Retired

$123(24.6)$

Monthly income

Minimum wage or less

Up to $\times 2$ of minimum wage $206(41.2)$

More than $\times 2$ of minimum wage

$76(15.2)$

Marital status

Maried

$379(75.8)$

Single

Divorsed $36(7.2)$

Family history of colorectal cancer in

first degree relatives

\begin{tabular}{|c|c|}
\hline Yes & $57(11.4)$ \\
\hline No & 443 (88.6) \\
\hline \multicolumn{2}{|l|}{ Smoking } \\
\hline Yes & $162(32.4)$ \\
\hline No & $338(67.6)$ \\
\hline \multicolumn{2}{|l|}{ Alcohol use } \\
\hline Yes & $46(9.2)$ \\
\hline No & $454(90.8)$ \\
\hline \multicolumn{2}{|c|}{$\begin{array}{l}\text { Regular exercise (min. } 150 \text { minutes per } \\
\text { week) }\end{array}$} \\
\hline Yes & $195(39.0)$ \\
\hline No & $305(61.0)$ \\
\hline
\end{tabular}


Table 2. The answers of participants about knowledge of colorectal cancer and its screening

\begin{tabular}{lccc}
\hline Questions & $\begin{array}{c}\text { Yes } \\
\mathbf{n}(\mathbf{\%})\end{array}$ & $\begin{array}{c}\text { No } \\
\mathbf{n}(\%)\end{array}$ & $\begin{array}{c}\text { No idea } \\
\mathbf{n}(\%)\end{array}$ \\
\hline Have you ever heard of colorectal cancer? & $454(90.8)$ & $28(5.6)$ & $18(3.6)$ \\
Know Fecal Occult Blood Test is available for CRC? & $196(39.2)$ & $62(12.4)$ & $242(48.4)$ \\
Know Sigmoidoscopy is available for CRC? & $67(13.4)$ & $32(6.4)$ & $401(80.2)$ \\
Know Colonoscopy is available for CRC? & $368(73.6)$ & $25(5.0)$ & $107(21.4)$ \\
$\begin{array}{l}\text { Most patients can survive CRC if it is found early and } \\
\text { removed? }\end{array}$ & $294(58.8)$ & $38(7.6)$ & $168(33.6)$ \\
\hline
\end{tabular}

$\mathrm{CRC}=$ Colorectal Cancer

about type 2 diabetes which increases the risk of colorectal cancer in $(36.5 \%$ vs $19.4 \%, p<0.001)$. Individuals over 45 years of age had more information about the fact that obesity increases the risk of colorectal cancer $(68.1 \%$ vs $52.6 \%, p<0.001)$. Those with normal BMI had more information about the applicability of colonoscopy as a screening method ( $80.9 \%$ vs $68 \%$ vs $74.5 \%, p=0.017$ ).

Individuals at higher education level had more information about the applicability of colonoscopy as a screening method $(64.2 \%$ vs $78.8 \%$ vs $84.7 \%, p<$ $0.001)$. Individuals at higher education level had more information about the lack of vegetables and fruits in the diet that increased the risk of colorectal cancer $(36.8 \%$ vs $42.4 \%$ vs $64.7 \%, p<0.001)$. Individuals who have job was more aware about using sigmoidoscopy as a screening method (18.6\% vs $10.4 \%$ vs $8.9 \%, p=0.016)$. Working Individuals had more information about the applicability of colonoscopy as a screening method $(78.9 \%$ vs $64.7 \%$ vs $77.2 \%, p=0.005)$. Retired individuals were more familiar with the increased risk of type 2 diabetes for colorectal cancer $(26 \%$ vs $26.6 \%$ vs $40.7 \%, p=0.010)$. Individuals who have more monthly income more information about the applicability of colonoscopy as a screening method $(63.3 \%$ vs $77.6 \%$ vs $81.6 \%, p<$ 0.001).

Individuals with more monthly income were more aware about low percentage of vegetables and fruits in the diet which increases the risk of colorectal cancer (37.2\% vs $48.1 \%$ vs $51.3 \%, p=0.028)$. Individuals who had more monthly income about low fiber intake

Table 3. The answers of the participants about the knowledge of the risk factors of colorectal cancer

\begin{tabular}{|c|c|c|c|}
\hline Questions & $\begin{array}{l}\text { Yes } \\
\text { n (\%) }\end{array}$ & $\begin{array}{c}\text { No } \\
\text { n }(\%)\end{array}$ & $\begin{array}{l}\text { No idea } \\
\text { n (\%) }\end{array}$ \\
\hline Getting older increases the risk of CRC? & $196(39.2)$ & $132(26.4)$ & $172(34.4)$ \\
\hline $\begin{array}{l}\text { A diet lack of fruits and vegetables increases the risk of } \\
\text { CRC? }\end{array}$ & $219(43.8)$ & $112(22.4)$ & $169(33.8)$ \\
\hline $\begin{array}{l}\text { A family history of colorectal cancer increases the risk } \\
\text { of CRC? }\end{array}$ & $326(65.2)$ & $67(13.4)$ & $107(21.4)$ \\
\hline $\begin{array}{l}\text { A diet that is high in fat and low in fiber increases the } \\
\text { risk of CRC? }\end{array}$ & $293(58.6)$ & $45(9.0)$ & $162(32.4)$ \\
\hline Smoking increases the risk of CRC? & $337(67.4)$ & $53(10.6)$ & $110(22.0)$ \\
\hline Having type 2 diabetes increases the risk of CRC? & $149(29.8)$ & $70(14.0)$ & $281(56.2)$ \\
\hline Lack of physical activity increases the risk of CRC? & $292(58.4)$ & $62(12.4)$ & $146(29.2)$ \\
\hline Being overweight or obese increases the risk of CRC? & $310(62.0)$ & $45(9.0)$ & $145(29.0)$ \\
\hline
\end{tabular}

$\mathrm{CRC}=$ Colorectal Cancer 
and high fat intake which increase the risk of colorectal cancer $(50.5 \%$ vs $63.6 \%$ vs $68.4 \%, p=$ $0.004)$. Individuals with more earnings per month than fatness increased the risk of colorectal cancer $(54.6 \%$ vs $66 \%$ vs $72.4 \%, p=0.007)$. Widow individuals had more information about colorectal cancer family history as a risk factor for colorectal cancer $(62.5 \%$ vs $70.6 \%$ vs $80.6 \%, p=0.049$ ). Individuals with a family history of colorectal cancer had more information about the applicability of colonoscopy as a screening method $(89.5 \%$ vs $71.6 \%, p=0.004)$. Individuals with a family history of colorectal cancer had more information about the colorectal cancer family history as a risk factor for colorectal cancer $(78.9 \%$ vs $63.4 \%$, $p=0.021)$.

Individuals who made regular exercise had more information about the use of FOBT in colorectal cancer screening $(47.2 \%$ vs $34.1 \%, p=0.003)$. Also they were more informed about the applicability of colonoscopy as a screening method $(78.5 \%$ vs $70.5 \%$, $p=0.049$ ). Individuals who made regular exercise were more likely to know that the lack of vegetables and fruits in the diet increases the risk of colorectal cancer $(51.8 \%$ vs $38.7 \%, p=0.004)$. Individuals who performed regular exercise were more aware about that colorectal cancer family history was a risk factor for colorectal cancer $(71.8 \%$ vs $63.4 \%, p=0.021)$. Individuals who had regular exercise were more aware about dietary fiber intake and fatty foods increases the risk of colorectal cancer $(70.3 \%$ vs $51.1 \%, p=0.000)$. Individuals who made regular exercise had more information about smoking which increases the risk of colorectal cancer $(72.8 \%$ vs $63.9 \%, p=0.039)$. Individuals performed regular exercise were more familiar with the lack of physical activity which increase the risk of colorectal cancer $(69.2 \%$ vs $51.5 \%$, $p<0.001)$. Also they were more aware about the obesity as a risk factor for colorectal cancer $(73.3 \%$ vs $54.8 \%, p<0.001)$.

\section{DISCUSSION}

Colorectal cancer accounts for $10 \%$ of all cancers and may develop sporadically, familially, or secondary to an inflammatory disease. Colorectal cancer is often described as a lifestyle disease and its incidence is higher in sedentary populations with a high fat and caloric intake [3]. In some studies, it has been reported that $70 \%$ of colorectal cancer can be prevented by life style changes [15].

According to the American Cancer Society colorectal cancer screening guideline, the recommended age for starting colorectal cancer screening decreased form 50 to 45 years old. It is also recommended, FOBT should be tested for every year, flexible sigmoidoscopy should be performed once in five years and colonoscopy should be performed once in ten years. That tests should be continued until at least 75 years of age [16]. In studies related to the awareness of colorectal cancer screening programs, it is seen that wareness of people about colorectal cancer screening programs vary according to the region. In a study about colorectal cancer screening from Saudi Arabia, $37.2 \%$ of the participants of this study were aware about colorectal cancer screening tests [17], whereas in a study from the United States, $96 \%$ of the participants were aware about colorectal cancer screening tests [12]. In a study from Lebanon, 55\% of the participants had awareness about colorectal cancer screening methods [13]. In one such study by Tastan et al. [11] 90\% of individuals not awared about the colorectal cancer screening programs. In another study by Baran et al. [18], 85.7\% of women individuals did not know about colorectal cancer screening methods. In many studies, a positive relationship was seen between education level and awareness of colorectal cancer screening methods [17,19-21]. In a study that included 132 volunteers and examined colorectal cancer screening methods in individuals over the age of 50 , it was observed that $10.7 \%$ of the individuals had a stool occult blood test and 9.2\% had a colonoscopy [22]. In the sub-analysis of the study, it was determined that women, non-smokers participants who did not drink alcohol and made regular exercise had more stool occult blood screening tests [22]. While $90.8 \%$ of the participants in our study had heard of colorectal cancer before, $77 \%$ of them knew at least one of the colorectal cancer screening methods. However, a large proportion of volunteers have no idea about sigmoidoscopy. The probable reason for this is that a large number of volunteers do not know what sigmoidoscopy is or do not know the difference between colonoscopy and sigmoidoscopy. Our study has higher levels of awareness of screening tests compared to many other studies, and the probable 
cause is that, patients admitted to our outpatient clinic with symptoms such as gastrointestinal bleeding had a chance to have information about colorectal cancer before they come to our outpatient clinic with a variety of sources. In our study, in accordance with the literature, a positive relationship was observed with the increase in the level of education on the awareness of colorectal cancer screening methods.

Considering that diet, life style and education play an important role in the prevention of colorectal cancer, knowledge of risk factors helps prevent colorectal cancer development $[3,23]$. There are many studies examining the effect of risk factors on screening programs $[24,25]$. In one study, it was reported that smokers participated in cancer screening programs were lesser that non-smokers and in another study, obese women were less included in colorectal cancer screening programs compared to normal weighted women $[24,25]$. In a study which had measured the knowledge level of colorectal cancer with 92 volunteers which are over 55 years oldobserved that they had risk factors associated with colorectal cancer, did not have the desired level of knowledge about the disease, and did not use early diagnosis methods adequately [26]. Although our study did not examine the participation rates of patients in screening programs, however it was found that individuals over 45 years of age, higher educated, working, and earning more monthly, a family history of colorectal cancer, and those exercising regularly had a higher level of awareness about colorectal cancer screening and risk factors.

In a study on the awareness of colorectal cancer risk factors and symptoms on 371 volunteers the risk and symptoms were reported $17.2 \%$ and $31.5 \%$ respectively. In the same study, it was reported that the most known risk factors were red meat eating, smoking and intestinal diseases, and the least known risk factors were diabetes and physical exercise [13]. In one study, it was reported that obesity is more associated with colorectal cancer and other gastrointestinal cancers [26]. Baran et al. [18] reported that $72.4 \%$ of the participants of this study were aware about obesity as a risk factor of colorectal cancer. In our study, smoking, family history and obesity were the most well-known risk factors, while the least known risk factors were age, type 2 diabetes and poor nutrition from vegetables.

\section{Limitations}

Limitations of our study include the small number of participants and the fact that no comparative study was performed with patients who applied to any outpatient clinic except general surgery.

\section{CONCLUSION}

Our study had higher awareness rates of screening and risk factors of colorectal cancer than many developing countries, however higher levels of awareness were needed. It is understandable that these rates are higher than the literature when it is thought that the individuals who participated in the study were patients who applied to a outpatients clinic with knowledge of gastrointestinal diseases. It is possible to increase these rates by providing education to the patients on cancer awareness, improving education level and living conditions.

\section{Conflict of interest}

The authors disclosed no conflict of interest during the preparation or publication of this manuscript.

\section{Financing}

The authors disclosed that they did not receive any grant during conduction or writing of this study.

\section{REFERENCES}

1. World Health OrganizationGeneva: Fact sheets;c2018. Available

at:http://www.who.int/news-room/fact-

sheets/detail/cancer/Accessed August 03, 2019.

2. Knaul FM, Arreola-Ornelas H, Méndez O, Alsan M, Seinfeld J, Marx A, et al. The global economic burden of cancer. In: Stewart BW, Wild CP, editors. World cancer report 2014. Lyon: International Agency for Research on Cancer; 2014:576.

3. Bosman FT. Colorectal cancer. In: Stewart BW, Wild CP, editors. World Cancer Report 2014. Lyon: International Agency for Research on Cancer; 2014:392- 393.

4. Eser SY, Karakılınç H. Cancer incidence in Turkey. In: Tuncer M, editor. Cancer Control in Turkey. Ankara: Ministry of Health Publication; 2010:35.

5. Eser S, Yakut C, Özdemir R, Karakilinç H, Özalan S, Marshall SF, et al. Cancer incidence rates in Turkey in 2006: a detailed registry based estimation. Asian Pac J Cancer Prev 2010;11:1731-9. 
6. Şahin NS, Üner BA, Aydın M, Akçan A, Gemalmaz A, Dişçigil $\mathrm{G}$, et al. [Knowledge of, attitudes toward, and barriers to participation of colorectal cancer screening in Aydin central region]. Türk Aile Hek Derg 2015;19:37-48. [Article in Turkish] 7. Koo JH, Leong RW, Ching J, Yeoh KG, Wu DC, Murdani A, et al. Knowledge of, attitudes toward, and barriers to participation of colorectal cancer screening tests in the Asia-Pacific region: a multicenter study. Gastrointest Endosc 2012;76:126-35. 8. Dziki Ł, Puła A, Stawiski K, Mudza B, Włodarczyk M, Dziki A. Patients' awareness of the prevention and treatment of colorectal cancer. Pol Przegl Chir 2015;87:459-63.

9. Andsoy II, Gul A. Breast, cervix and colorectal cancer knowledge among nurses in Turkey. Asian Pac J Cancer Prev 2014;15:2267-72.

10. Kaya O, Hoca O, Kulaçoğlu H. Knowledge and awareness of auxiliary health personnel about colorectal cancer. Turk J Gastroenterol. 2013;24:339-44.

11. Tastan S, Andsoy II, Iyigun E. Evaluation of the knowledge, behavior and health beliefs of individuals over 50 regarding colorectal cancer screening. Asian Pac J Cancer Prev 2013;14:5157-63.

12. Brandt HM, Dolinger HR, Sharpe PA, Hardin JW, Berger FG. Relationship of colorectal cancer awareness and knowledge with colorectal cancer screening. Colorectal Cancer 2012;1:383-96. 13. Tfaily MA, Naamani D, Kassir A, Sleiman S, Ouattara M, Moacdieh MP, et al. Awareness of colorectal cancer and attitudes towards its screening guidelines in Lebanon. Ann Glob Health 2019;85:75.

14. Briant KJ, Wang L, Holte S, Ramos A, Marchello N, Thompson B. Understanding the impact of colorectal cancer education: a randomized trial of health fairs. BMC Public Health 2015;15:1196.

15. Ueland AS, Hornung PA, Greenwald B. Colorectal cancer prevention and screening: a Health Belief Model-based research study to increase disease awareness. Gastroenterol Nurs 2006;29:357-63.

16. Wolf AMD, Fontham ETH, Church TR, Flowers CR, Guerra

$\mathrm{CE}$, LaMonte SJ. Colorectal cancer screening for average-risk adults: 2018 guideline update from the American Cancer Society. CA Cancer J Clin 2018;68:250-81.

17. Khayyat YM, Ibrahim EM. Public awareness of colon cancer screening among the general population: a study from the Western Region of Saudi Arabia. Qatar Med J 2014;2014:17-24.

18. Baran GK, Pinar G, Sahin S. Determination of risk factors, knowledge level and awareness towards colorectal cancers among Turkish women. J Behav Health 2016;5:109-16.

19. Nemer H, Hejase A, Hejase H, Othman M, Chawraba M, Trad MA. Colorectal cancer: exploring awareness in Lebanon. J Middle East North Afr Sci 2016;2:10-21.

20. Bidouei F, Abdolhosseini S, Jafarzadeh N, Izanloo A, Ghaffarzadehgan K, Abdolhosseini A, et al. Knowledge and perception toward colorectal cancer screening in east of Iran. Int J Health Policy Manag 2014;3:11-5.

21. Lynes K, Kazmi SA, Robery JD, Wong S, Gilbert D, Thaha MA. Public appreciation of lifestyle risk factors for colorectal cancer and awareness of bowel cancer screening: a cross-sectional study. Int J Surg 2016;36:312-8.

22. Causey C, Greenwald B. Promoting community awareness of the need for colorectal cancer prevention and screening: a replication study. Gastroenterol Nurs 2011;34,34-40.

23. Byrne MM, Davila EP, Zhao W, Parker D, Hooper MW, Caban-Martinez A, et al. Cancer screening behaviors among smokers and non-smokers. Cancer Epidem 2010;34,611-7.

24. Messina CR, Lane DS, Anderson JC. Body mass index and screening for colorectal cancer: gender and attitudinal factors. Cancer epidemiology. Cancer Epidemiol. 2012;36,400-8.

25. Kalkım A, Dağhan Ş, Taşkın C. Examination knowledge levels of elderly people about colorectal cancer's risks and early diagnosis and their this cancer's risks. Süleyman Demirel Univ Health Sci J 2014;5:88-93.

26. Yilmaz M, Dereli F, Yelten G. [Some sociodemographic characteristics, healthy lifestyle behaviors and health beliefs of individuals aged 50 and over effect on screening behaviors of colon cancer]. Hemşirelikte Eğitim ve Araştırma Dergisi 2016;13:226-34. [Article in Turkish] 